\title{
DALTON TREVISAN: NARRATIVA, CIDADE E URBANISMO
}

\author{
DALTON TREVISAN: NARRATIVE, CITY AND URBANISM \\ DALTON TREVISAN: NARRATIVA, CIUDAD Y URBANISMO
}

Clovis Ultramari - Pontifícia Universidade Católica do Paraná - Curitiba - Paraná - Brasil

ultramari@yahoo.com

\begin{abstract}
Manoela Massuchetto Jazar - Pontifícia Universidade Católica do Paraná - Curitiba - Paraná - Brasil manoelamj.arq@gmail.com
\end{abstract}
Diego Luís Fock Pereira - Pontifícia Universidade Católica do Paraná - Curitiba - Paraná - Brasil
diegofock@ymail.com

\section{Resumo}

0 contexto maior deste artigo é o diálogo interdisciplinar entre urbanismo e literatura. 0 diálogo é restrito à tomada da literatura como fonte e à sua leitura pelo viés estritamente urbanístico. A partir da seleção de cinco obras de Dalton Trevisan, recorrentemente consideradas representativas de sua produção, servimonos da geografia do mundo curitibano do autor, das suas referências a elementos e compartimentos dessa cidade, e de possíveis relações temporais entre narrativas e mudanças implantadas em Curitiba por um urbanismo iniciado nos anos 1970 e com apogeu na década de 1990. Concluímos por uma fragilidade na consideração do autor como crítico explícito a esse urbanismo; reiterando a importância da leitura da sua obra por perspectivas distintas da dos estudos literários como ferramentas provocadoras de debates e de novos temas de investigação.

Palavras-chave: Cartografias literárias, Dalton Trevisan, Curitiba.

\section{Abstract}

The main context of this article is the interdisciplinary dialogue between urbanism and literature. This dialogue is limited to the use of literature as a source of information and to its reading oriented to urbanistic perspectives. It is based on five selected works by the Brazilian author Dalton Trevisan, mostly considered as reference among his decades-long production. It uses the author's geography of the city of Curitiba, its references to this city's elements and compartments, and possible temporal relations between his text and the urban changes implemented by a certain urbanism adopted in the early 1970's and that would have its culmination in the 1990's as instigations to debate about the city. Final considerations reiterate a fragile consideration of the author as a critic of such urbanism yet confirming the importance of his work as source by distinct perspectives, not only from literary fields, suggesting further debates and new investigative topics. Keywords: Literary cartographies, Dalton Trevisan, Curitiba.

\section{Resumen}

El contexto mayor de este artículo es el diálogo interdisciplinario entre urbanismo y literatura. El diálogo está restringido a la toma de la literatura como fuente y a su lectura por el sesgo estrictamente urbanístico. A partir de la selección de cinco obras de Dalton Trevisan, recurrentemente consideradas representativas de su producción, nos servimos de la geografía del mundo curitibano del autor, de sus referencias a elementos y de compartimentos de esa ciudad y de posibles relaciones temporales entre narrativas y cambios implantados en Curitiba por un urbanismo iniciado en los años 1970 y con apogeo en la década de 1990. Al concluir, 
observamos una fragilidad en la consideración del autor como crítico explícito a ese urbanismo; reiterando la importancia de la lectura de su obra por perspectivas distintas de la de los estudios literarios como herramientas provocadoras de debates y de nuevos temas de investigación.

Palabras clave: Cartografías literarias, Dalton Trevisan Curitiba.

Introdução

este artigo reitera estudos anteriores dos mesmos autores que tratam da dificuldade de se encapsular a realidade complexa de uma cidade por meio de esforços conceituais. Ainda que reconhecida essa dificuldade, debates epistemológicos sobre o fenômeno urbano e a cidade selecionam, espontânea ou propositadamente, elementos que possam conceituar, inconclusivamente, esse todo de difícil síntese. O debate aqui apresentado assume, pois, que as escolhas desses elementos por um autor serão sempre fractais da realidade urbana.

Por meio de literatura selecionada do curitibano Dalton Trevisan (1925 - ), discutem-se elementos catalisadores da imagem de uma cidade, ou seja, os elementos utilizados para sintetizá-la. A Curitiba de Dalton Trevisan seria restrita à perspectiva do seu autor e, mais ainda, à interpretação daquele que o lê. Da perspectiva do leitor mais geral terse-ia uma cidade com recortes geográficos limitados - motivo de nossa discussão a seguir - e um estrato social algumas vezes generalizado como a "hipocrisia da classe média". Da parte do leitor específico, que vê nessa literatura uma das fontes para se discutir um determinado urbanismo, o conceito de cidade deve ser tomado como em constante elaboração, a partir da identificação dos diversos elementos que o autor, Dalton Trevisan, utiliza para descrever Curitiba. Para o segundo leitor a cidade não apenas é entendida como a consubstanciação do mundo urbano, de modo concreto, conforme Lefebvre (1999), mas também como algo "líquido" (Crestani; Ultramari; Oliveira, 2017), um objeto de difícil compreensão e que rejeita conceitos definitivos e imutáveis. Ainda para esse segundo tipo de leitor, quem escreve sobre uma cidade ou situa sua narrativa no ambiente urbano, faz, sob a perspectiva que lhe é particular, uma reflexão autoral sobre o fenômeno urbano. Essa reflexão se apresenta na forma de cenário, impositor ou revelador de conflitos e experiências humanas diversas.

$\mathrm{Na}$ perspectiva da leitura aqui realizada, segundo interesses urbanísticos, ela igualmente reflete a interpretação influenciada por experiência e interesses pessoais, tal qual, por exemplo, lembrada pelos 
obstáculos epistemológicos de Bachelard (2006); e a experiência da crítica literária que valoriza ora a estrutura do texto, ora sua recepção pelo leitor (Rabenhorst, 2002).

Entretanto, tem-se aqui o objetivo operacional, que é o de debater a cidade por meio da leitura de obras literárias com vieses tão-somente urbanísticos, buscando no texto menções que possam suscitar uma discussão sobre uma cidade em particular ou sobre o fenômeno urbano mais amplo. Seguimos essa opção consciente de que usar um texto é diferente de interpretá-lo, conforme lembrado por Umberto Eco (2008). Assim, seu pressuposto é o de que a literatura pode se constituir em fonte adicional de pesquisa sobre a cidade, seja na discussão sobre seu próprio conceito, seja na caracterização de uma cidade específica.

Ainda sobre o contexto do artigo, é importante observar que integra pesquisa maior onde discutimos como ideias referentes à cidade permanecem ou são descartadas em diferentes recortes temporais e como circulam entre diferentes campos científicos. Essa temática ampliada e a perspectiva de apreendê-la por meio da literatura reconhecem a multiplicidade e a efemeridade no entendimento sobre a gestão urbana e determinação de suas prioridades. Reconhece, pois, a existência de períodos distintos no modo de pensar e gerir as cidades, de pensar o urbanismo segundo uma já longa alternância de modelos. Para o caso brasileiro, essa alternância ou periodizações está presente no trabalho de autores diversos (Feldman, 2001; 2014; Leme, 1999; Santos, 1994; Ultramari; Firkowski, 2012). À cada época, em novas prioridades e novas perspectivas de compreensão da cidade, ideias e práticas referenciais sobre o espaço urbano são alteradas, complementadas, reafirmadas e, ainda que mais raramente, rejeitadas de modo radical. No recorte temporal das obras selecionadas, vivencia-se no Brasil uma transição entre a valorização da cidade funcional do planejamento estatal iniciada no final dos anos 1960 e a da cidade neoliberal, competitiva e iconográfica dos anos 1990. Tais extremos no ideário urbanístico, vivenciados para o caso de uma Curitiba planejada que inicia com a aprovação de seu Plano Diretor de 1966 e implementações urbanas no início da década de 1970, são buscados na narrativa de obras selecionadas de Dalton Trevisan (1925 -) com início em 1964 e término em 1992 (anos de primeira edição).

A produção literária de Dalton Trevisan é comumente relacionada com a cidade onde nasceu e sobre a qual faz referências explícitas. 
Relações similares são também identificadas em outros autores, com especificidades narrativas e uma maior ou menor explicitação do espaço urbano; de uma longa lista de brasileiros, este é o caso da relação entre Rio de Janeiro com Lima Barreto e Machado de Assis, entre Salvador e Itabuna com Jorge Amado, Manaus com Milton Hatoum, Sertão de Minas/ Bahia com Guimarães Rosa, São Paulo com Mário de Andrade e Guilherme de Almeida.

A implementação do chamado urbanismo curitibano tem também como referenciais a primeira gestão do prefeito Jaime Lerner (1937 -) e a criação e o fortalecimento do Instituto de Pesquisa e Planejamento Urbano de Curitiba/ IPPUC (criado em 1965). A imagem mais comum que se vê difundida dessa cidade é aquela cuja gestão teria avançado e se distinguido nacional e internacionalmente nas áreas de uso do solo, transporte, áreas verdes e projetos iconográficos (Szuchman, 2017). A Curitiba contemporânea e encapsulada nessas áreas de atuação da gestão urbana passa a ser então buscada nas obras de Dalton Trevisan; todavia, a leitura mais comum que se tem é a de que o autor revela uma outra Curitiba, que não aquela da espetacularização de uma cidade que se quis Primeiro Mundo (vide, entre uma grande produção nacional crítica a essa pretensão, Sanchez, 1997). Não se discute aqui qual a Curitiba, revelada ou vista de uma ou de outra maneira, é a representação da verdade; ao contrário, rejeita-se tomá-la como única, e não entendê-la por suas partes complementares, e não visualizá-la com mais ou com menos otimismo, júbilo, crítica e ceticismo. Ainda que tais sínteses sobre uma cidade fossem possíveis, restam as diferentes intenções e responsabilidades da literatura e do urbanismo; de um lado, a liberdade criativa e opções estilísticas, de outro, a submissão a determinações administrativas, legais, técnicas e com compromissos com uma atuação universalizada e prioritariamente dirigida às parcelas de menor renda.

$\mathrm{O}$ atributo de observador atento a pormenores de uma realidade vivida, mas também o de detentor de uma personalidade declaradamente reclusa, de um pessimismo característico e posicionamentos comumente saudosistas (Rebinski, 2009) refletem na Curitiba narrada por Dalton Trevisan. De fato, para Nicolatto (2004), Trevisan busca continuamente reforçar a imagem de Curitiba como uma cidade provinciana, valorizando o tempo passado em um universo de memórias. 
Esta introdução é seguida de uma curta discussão sobre literatura, cidade e cartografia; esta última é uma das ferramentas utilizadas para se determinar a geografia urbana construída pela narrativa de Dalton Trevisan. A sobreposição cartográfica de elementos e compartimentos narrados com os da cidade real é acompanhada de uma sobreposição temporal da edição das obras com períodos do urbanismo na cidade. $\mathrm{Na}$ sequência, apresentam-se as obras selecionadas do autor, o estudo empírico e as considerações finais.

\section{Literatura e cidade}

No campo interdisciplinar literatura e cidade, para o interesse deste artigo, é possível observar uma circulação de ideias realizada, minimamente, a partir de dois focos investigativos: 1) relações entre obra literária e contexto urbano, ao modo, por exemplo, como têm sido recorrentemente analisados os romances de Machado de Assis e a cidade do Rio de Janeiro do começo dos anos 1900; e 2) relações entre obra literária e discurso político ou social, com possíveis interesses para a gestão pública das cidades, ao modo como se analisa a explicitação de posicionamentos sociais de autores de uma littérature engagée ou de combate, como Jorge Amado (vide Pontes, 2009) e o dito em textos político-administrativos de autores consagrados da literatura, como foi o caso de Graciliano Ramos com seus conhecidos relatórios de prefeito ao governador do Alagoas (vide Jazar, 2015). Na análise dessas relações, observa-se uma circulação de ideias, ora entre obras distintas de um mesmo autor e sua cidade de recorrência temática, ora entre essas mesmas obras e as explicitadas em outros campos profissionais do autor.

Diferentemente da história que busca descrever e entender o passado, a literatura pode nos dizer aquilo que poderia ter sido (Nascimento, 2014). A literatura como fonte histórica direta, em tese, é menos abundante em termos de informações sobre o passado de uma determinada cidade; todavia, pode ser singular enquanto suporte para um entendimento sobre algo ainda a ser construído, a ser evitado, defendido ou rejeitado. Nesta perspectiva, ter-se-ia a identificação de uma cidade idealizada, criticada ou de seus agentes e recursos priorizados.

Desde suas primeiras manifestações no século XIX, a cidade passa a ser reconhecida como o lócus, majoritário, do mundo moderno. A Paris 
de Baudelaire (1821-1867), a qual se revela como a primeira forte evidência desse reconhecimento, é simbólica, revelando uma literatura que se diz moderna e também uma cidade que se impõe como modelo urbanístico, de uma maneira de se viver, de um mito, enfim, que adentraria triunfante no século XX (Ultramari; Ciffoni, 2015). Brocca (1993) fala dos mitos da cidade comumente criados por formas literárias de expressão, e que passam a constituir seu maior valor. A cidade competitiva que se firma como modelo a partir dos anos 1990 (vide extensa produção acadêmica brasileira sobre o tema), no Brasil e no mundo, assimila essa mesma máxima, servindo-se de ícones arquitetônicos, de intervenções simbólicas e mesmo do marketing urbano para também criar um mito. Seria a gestão urbana fazendo o papel que a literatura há muito havia feito. Tais mitos, ainda que enganosos ou fractais de uma realidade maior, revelam aquilo que, num determinado momento, uma determinada cidade desejou ser, acreditou ser ou mesmo impôs que algo assim o fosse.

Um dos instrumentos para a identificação de mitos urbanos criados ou mencionados pela literatura é a sua geografia ou cartografia. Tally Jr. (2011), ao discutir o tema das cartografias literárias, lembra-nos que escrever é também mapear:

Narrative itself is a form of mapping, organizing the data of life into recognizable patterns with it understood that the result is a fiction, a mere representation of space and place, whose function is to help the viewer or mapmaker, like the reader or writer, make sense of the world (Tally Jr., 2011).1

Ora, seja no recorte espacial adotado pela narrativa literária, seja nos referenciais urbanísticos empregados, seja ainda na descrição de relações sociais e econômicas, é possível encontrar uma fonte de informação assimilada no texto ou, facilitando o exercício investigativo, sua descrição em mapas. Seguindo esse mesmo raciocínio, Tally Jr. (2011), afirma: "If the writer is a mapmaker, the critic is a map-reader, who (like all mapreaders) also creates new maps in the process". ${ }^{2}$

De modo geral, cartografia literária é definida como um instrumento do campo da literatura. Piatti, Reuschel e Hurni (2009, p. 3), sempre referenciados quando se debate este tema, o conceituam como algo: "being able to provide one possible method, more precisely: tools in order to explore and analyse the particular geography of literature". ${ }^{3}$ Esse conceito trazido por Piatti, Reuschel e Hurni revela uma perspectiva 
mais especificamente preocupada em disponibilizar uma ferramenta complementar na análise da obra literária e não como instrumento adicional na discussão de uma cidade ou mesmo de um processo urbano em níveis ampliados. No campo do urbano, parece haver ainda uma limitação no volume de produção concernente; vide exceção recente para o caso de Martins (2017), ao discutir a Moscou e São Petersburgo na obra de Dostoiévski. No campo da literatura, o exercício é recorrente. Mesmo assim, é conhecida a observação desalentadora de Virginia Woolf (18821941) sobre a limitação de se entender uma obra ou mesmo a intenção de um escritor por meio de cartografias. Em texto de 1905, baseada no ceticismo de se ensaiar relações entre ficção e realidade, ela diria: "A writer's country is a territory within his own brain, and we run the risk of disillusionment if we try to turn such phantom cities into tangible brick and mortar"4 (Woolf, 1986, p. 35). Na defesa dessa cartografia, Turchi (2004, apud Kokula, 2016) diria que é uma ferramenta para se adentrar num mundo eventualmente desconhecido. Do mesmo modo, Piatti et al. (2012, p. 180) identifica a possibilidade de se mapear "tudo o que se quer":

Modern cartography has the ability to map almost any phenomenon for which spatial relationships are of primary relevance. While existing cartographic products cover already an enormous variety of topics, the visualisation of 'other' geographies gains more and more attention. ${ }^{5}$

Para o caso mais distante, que é o do mapeamento da obra literária não para sua compreensão ou para sua familiarização, mas sim para o entendimento complementar de processos urbanos, a defesa de seu uso está na busca de uma fonte pouco usual, na ampliação de perspectivas analíticas, no exercício interdisciplinar e, enfim, na eventual redução de vazios investigativos (Ultramari; Jazar, 2016).

O estudo empírico que se apresenta reconhece essas possibilidades investigativas e esses pressupostos. Na busca de elementos para o debate sobre o urbanismo de Curitiba em obras selecionadas de Dalton Trevisan, a cartografia é utilizada como ferramenta não para se identificar o universo do autor, mas sim para identificar um fenômeno - o urbano sempre revelado em partes. Do mesmo modo, os mitos de Curitiba são considerados pela perspectiva de sua criação pelo urbanismo, ora aceitos, ora rejeitados, ora verdadeiros, ora manipulados. 


\section{Dalton Trevisan e suas obras selecionadas}

o urbanismo e a gestão de Curitiba, por suas prioridades, implementações e assimilação pela população local e externa, podem ser identificados no percurso histórico das décadas de 1960, 1970, 1980 e 1990. As obras selecionadas de Dalton Trevisan seguem um percurso temporal similar: Cemitério de Elefantes (1964), O Vampiro de Curitiba (1965), Mistérios de Curitiba (1968), A Polaquinha (1985) e Em Busca de Curitiba Perdida (1992). O modelo Curitiba de urbanismo, ou de planejamento e gestão, é assim sobreposto à Curitiba de Dalton, buscando-se discutir: 1) a apreensão autoral de mudanças na cidade ou de sua forma de pensá-la e de geri-la; e 2) o eventual posicionamento de combate frente a um urbanismo específico.

Nesta época [início do reconhecimento de Dalton Trevisan], durante a primeira administração do urbanista Jaime Lerner, Curitiba também tinha os olhos da intelectualidade brasileira voltados para si, motivados pelo arrojado projeto urbanístico que aí se desenvolvia, o cenário de cartão postal, rapidamente executado e largamente divulgado pela mídia, acabava, assim, por se colar ao autor (Comitti, 1996, p. 82).

De antemão, o que se tem como recorrente é o entendimento de que a temática underground desenvolvida por Trevisan sugere a representação de uma "Curitiba esquecida” ou, conforme Nicolato (2004, p. 129), "Curitiba muitas vezes, cenário de dilemas urbanos pouco revelados pela prática da gestão urbana ou motivo de seu planejamento e políticas públicas”. Do mesmo modo, Vieira (2013, p. 152) anuncia, de pronto, a distinção entre uma Curitiba idealizada, uma Curitiba real e uma Curitiba descrita por Dalton: "a imagem do drama ontológico dos curitibanos dramatizados na obra trevisaniana parece desmentir o sucesso desse planejamento modernizante”. Complementarmente, Vieira reitera uma contradição entre a abstração de um espaço mental, conforme revelado por Simmel (1969), ou aquele visualizado pelo planejador urbano e o espaço vivido, conforme entendido por Lefebvre (1974). De um lado, a realidade, que entendemos como múltipla e só possível de ser vivida fractalmente; de outro, o idealizado pelo planejamento e/ou o sentido pelo indivíduo que o traduz em produção literária. 
Tais dicotomias transformam-se no tema recorrente quando de um debate "urbanístico" sobre a obra de Dalton. Porém, a Curitiba real ou planejada que se busca criticada na obra de Dalton tem recorte temporal, político e projetual bastante definidos. Essa Curitiba é aquela que surge no início dos anos 1970, com a implementação do Plano Diretor de 1966 e que estabeleceria uma paisagem urbana de difícil desconstrução. Ao mesmo tempo, a Curitiba que se busca na obra de Dalton Trevisan é a de um grupo político satelizado no nome do arquiteto Jaime Lerner, o qual se faz prefeito pela primeira vez em 1971. Nicolatto (2004), por exemplo, sugere um autor que não mais reconhece a cidade onde mora por conta da transformação urbana trazida "com o progresso acelerado e os planos urbanísticos” (p. 129). Porém, na década de 1950, por exemplo, Dalton nos revela uma Curitiba provinciana, úmida, com rios ameaçadores, de pessoas tuberculosas e sofridas por um inverno sem fim. Em termos de serviços urbanos, Curitiba era também uma cidade de carências: "A prefeitura ignorava-lhe o curso subterrâneo; o rio de pobre, não fora o Belém, com que água as mães dariam nos piás o banho de sábado?”, escreve Trevisan em sua obra de 1959, Novelas nada exemplares (1979, p. 47).

Dalton Trevisan é reconhecido pela personalidade reclusa e pelo perfil "programático e obsessivo que traça o itinerário de uma busca incessante, manifestada na repetição de situações, de personagens, de um tema que se multiplica em voltas infindáveis" (Waldman, 2007, p. 255). Adotando uma estética minimalista, recorre, ainda que quase sempre a partir de personagens de classes média-baixa e baixa, à "penúria econômica, a relações escabrosas, injustiça social e perigos urbanos" (Vieira, 2013, p. 153). Sinteticamente, a retórica adotada por Dalton Trevisan é, pois, claramente direcionada à representação social da sociedade curitibana, especialmente a partir da década de 1960 (Rosalino, 2002). Do mesmo modo, Sanchez Neto (1998) descreve a Curitiba de Dalton como a dos moradores da invisibilidade, de uma cidade que nega a si própria.

A despeito de uma permanência em relação a seus atributos literários e temáticas do início de sua carreira, Trevisan possui uma postura revisionista em relação a suas obras, e "está constantemente jogando com novas possibilidades de significação” (Sanches Neto, 1998, p. 17), justamente por isso parece atualizar-se em relação aos personagens vividos numa Curitiba mutante: num momento, criminosos, 
mendigos e favelados, na sequência, seguindo atualizações do cotidiano contemporâneo, o discurso de viciados em drogas, traficantes, ou ainda de novas seitas e grupos religiosos (Waldman, 2006).

Para Sanches Neto (1998), interpretar a obra significa também entender o contexto espacial no qual o autor estava inserido em determinado período. Mugiatti (2011) vai além e refaz o percurso literário de Dalton a partir do crescimento demográfico curitibano

A partir da década de 1970, meio a uma Curitiba mundialmente conhecida como referência de sustentabilidade e modernidade no panorama latino-americano (Matias, 2013), o autor reitera o retrato do avesso. Todavia, é na explicitação de seus críticos que esse avesso faz às vezes de voz contrária ao urbanismo: “curitibanos dramatizados na obra trevisaniana parecem desmentir o sucesso desse planejamento modernizante" (Vieira, 2013, p. 152). Mais que isso, é reforçada a ideia de uma Curitiba provinciana que resiste a mudanças, presa "entre uma mentalidade rural e uma modernidade urbana, vivendo uma gestalt conflituosa entre lugar de passado e futuro" (Vieira, 2013, p. 158).

Portanto, a crítica veiculada por Dalton nem sempre seria possível tomá-la como dirigida ao idealizado pelo urbanismo curitibano, mas também como uma perspectiva pessoal de ver a cidade e mesmo seu ambiente natural: "Curitiba, que não tem pinheiros, essa Curitiba eu viajo. Curitiba, onde o céu azul não é azul, Curitiba que viajo. Não a Curitiba para inglês ver, Curitiba me viaja." (Trevisan, 1992, p. 7).

Em Cemitério de Elefantes (1964), a alusão ainda se refere ao meio rural, com habitantes marginalizados por um "mundo convencionalmente moderno”. Em O Vampiro de Curitiba (1965), o processo de urbanização se impõe como irreversível: roubos, estupros e outras formas de violência urbana expostos nas falas de Nelsinho, o protagonista delineado como um "homem curitibano ordinário". Todavia, é na década de 1990 que a Curitiba antiga parece desaparecer em definitivo das diretrizes urbanísticas; evidenciam-se processos de gentrificação na cidade, manobras políticoeconômicas "modernizadoras", discurso ecológico e atração de capital (Carvalho, 2013). A crítica a essas diretrizes não são explícitas, mas o não dito pode, também, ser tomado como uma veemência. No explícito, a reação melancólica não se faz necessariamente a um novo mundo, mas a um mundo que se acaba, tal qual um juízo final. O texto "Lamentações de Curitiba”, na obra Em busca de Curitiba Perdida (Trevisan, 1992, p. 67) confirma: 
Ó Curitiba Curitiba Curitiba, escuta o grito do Senhor feito um martelo que enterra os pregos. Teu próprio nome será um provérbio, uma maldição, uma vergonha eterna. Curitiba, o Senhor chamou o teu nome e como o de Faraó rei do Egito é apenas um som. A espada veio sobre Curitiba, e Curitiba foi, não é mais.

O raciocínio que se desenvolve aqui é a respeito de uma possível recusa do cidadão Dalton Trevisan em se posicionar explicitamente frente às mudanças, ou permanências, protagonizadas pelo urbanismo curitibano; diz respeito também à possibilidade de esse mesmo autor referir-se a um processo urbano inerente às cidades brasileiras que já no final dos anos 1960 iniciavam um percurso de altas taxas de crescimento demográfico, de recepção do êxodo rural, de periferização e de demandas básicas não atendidas. Entre uma possibilidade e outra, sua obra é utilizada pela oposição ao grupo político hegemônico responsável pelo "modelo Curitiba de urbanismo" como porta-voz de uma crítica.

De modo geral, Trevisan se revela ao enaltecer a Curitiba de sua juventude, quase que sem menção explícita à nova iconografia arquitetônica da cidade. Desconsideração, desprezo, frente a uma cidade considerada de sucesso por muitos é entendida como crítica feroz. Enaltecimento do passado é entendido como ridicularização da epifania urbanística dos anos que marcariam a cidade de Curitiba no período 1970-1990. Sua reclusão doméstica é compreendida como crítica à recorrente celebração da cidade.

Importa também observar a opção pessoal de Dalton Trevisan: "eu acho a invisibilidade e a recolhidez de Trevisan uma coisa lindamente refrescante e refrescantemente linda”, afirma Galindo (2011, p. 11), como um aviso referente ao isolamento do autor em casa. Uma reclusão que talvez o presenteie com uma perspectiva ainda mais apurada para o grande processo de urbanização e metropolização da cidade, desviando seu olhar de períodos que considera mais curtos, passageiros. "Apesar de residente na cidade, ele sempre foi um étranger (Camus), um outsider (Colin Wilson), o autodenominado Vampiro, espreitando a vida de seus conterrâneos escondido nas sombras” (Muggiati, 2011, p. 19).

Na década de 1980, representada aqui pela obra $A$ Polaquinha (Trevisan, 1985), na terceira gestão do prefeito Jaime Lerner, a cidade vê surgir a alcunha de "Capital Ecológica" e "Capital de Primeiro Mundo", promovidas pela sua oficialidade, ora criticada, ora assumida como verdade mesmo entre habitantes até mesmo de sua espraiada 
Região Metropolitana. A valorização das etnias europeias presentes em Curitiba como uma das estratégias de seu urbanismo não convence Dalton Trevisan quando da descrição de sua personagem principal: sem nome, tal qual habitante múltiplo da cidade, pobre e descendente de poloneses. Entretanto, a escassez de referências concretas a essa apologia na obra de Dalton parece decepcionar o leitor ávido por apoio autoral explícito ao mundo urbano que o descontentava. De fato, na revisão desta obra contemporânea às celebrações aos imigrantes nos nomes e estruturas dos parques da cidade dos anos 1980, são restritas as menções explícitas ao concreto do novo projeto urbano. Há, sim, como já discutido, a constante exaltação do passado.

A década de 1990-2000, última desta análise, refere-se ao apogeu do modelo Curitiba, identificado na profusão de parques, programas ambientais e uma arquitetura característica pelo estilo e materiais utilizados, sempre com elementos tangíveis e de fácil veiculação pelas mídias. Nesta época, Dalton publica Em Busca de Curitiba Perdida (1992), em que questiona o excesso de pessoas e carros, critica as calçadas em que pedestres mal conseguem andar, condena a violência urbana e a poluição sonora. Faz referências a construções, ruas e bairros da cidade, sempre centrais, usa-os como ambientes para seus relatos e não como elementos de um urbanismo em escrutínio. Mais que tudo, fala do passado, critica o presente, fala de uma cidade de onde quer partir, mas da qual já sente saudades: "Não permita Deus que eu morra / sem eu daqui me vá / sem que eu diga adeus ao pinheiro / onde já não canta o sabiá / morrer ó supremo desfrute / em Curitiba é que não dá” (Trevisan, 1992, p. 51). Nesta mesma obra, ao final, no texto Curitiba Revisitada, Dalton Trevisan avança na crítica: "cidade irreal da propaganda / ninguém não viu não sabe onde fica” (1992, p. 71). Na maioria das vezes, os marcos da Curitiba contemporânea seriam possivelmente criticados por exclusão textual, por não menções e pelo enaltecimento de uma cidade que não mais existia, a da sua juventude.

Essa ausência pode também ser explicada pela opção que o autor faz em relatar aquilo que permanece e que parece coibir a entrada de novos elementos concretos do urbanismo. Na crítica à cidade, estão os seus atributos naturais, pequenos rios ocupados em suas margens por população pobre, submetidos à umidade e ao frio, conforme descrição da hidrografia local encontrada em Dalton por Muggiati (2011). 
A crítica social é majoritariamente feita pela defesa de grupos sociais excluídos e ignorados, que pouco usufruem do desenvolvimento propagado na década de 1990 da cidade de Curitiba. Este é um cenário que pode, entretanto, ser contextualizado no processo de urbanização brasileiro, o qual, a despeito de submeter-se a políticas diversas em termos de prioridades públicas, de ideais urbanísticos, de avanços legais, pouco logrou reverter seu cenário de cidades duais. A narrativa de Dalton Trevisan - que viveu em Curitiba por toda sua vida - traz uma crítica urbana que ultrapassa o tempo e o recorte político administrativo de sua cidade. Waldman (1982) sintetiza essa ideia ao encontrar na narrativa do autor "formas de contar à sociedade liberal de arremedo o que o chamado capitalismo tardiamente avançado produziu no Brasil e, quem sabe, em outros países que passaram e passam por processos de desenvolvimento mais ou menos semelhantes” (p. 128). No intuito da assimilação da narrativa literária como fonte de informações ou como provocadoras de um debate urbanístico, explicita-se aquilo que merece sempre ser avivado: a limitação da capacidade ou do interesse de um projeto urbano, de um modelo urbanístico, ou de diretrizes técnicas em compreender o todo urbano, e o compromisso desses mesmos fatores em denunciar injustiças, iniquidades e demandas básicas não atendidas. Na observação da crítica de Dalton Trevisan a esse cenário desigual vale, todavia, a revisão feita por Comitti (1996). Para este autor, a obra de Dalton Trevisan pode ser vista de dois modos distintos. Primeiramente, como documental, com destaque para os temas do cotidiano e sociais, tornando-se engajada, ainda que livre de qualquer movimento político. Pode também ser entendida livre do próprio engajamento, obcecada por uma nostalgia infinita. Para esta discussão é ainda mais relevante sua conclusão: “a Curitiba de Dalton Trevisan seria um cenário congelado da década de 40, sendo o tom memorialístico atenuado apenas pela atuação rarefeita do narrado e pela extrema concisão dos textos" (Comitti, 1996, p. 82).

$\mathrm{Na}$ continuidade da discussão sobre a explicitação ou a potencialidade da narrativa de Dalton Trevisan no debate de um projeto urbanístico, o item a seguir especializa sua geografia, identificando elementos/compartimentos urbanos e sua localização na grande malha da cidade. 


\section{Espacialização da obra trevisiana}

Na leitura das cinco obras de Dalton, foi possível identificar um total de cento e cinco referências espaciais concentradas em cinquenta e um pontos de Curitiba. Analisadas diacronicamente, as obras não permitem a identificação de um padrão cronológico de incremento ou redução de menções à cidade; contudo, chama atenção a concentração de referências na obra Em busca de Curitiba perdida, escrita nos anos 1990 e precisamente no momento em que, conforme Prestes (2018), as avaliações externas a Curitiba e sua autoavaliação são mais intensas e positivas. No conjunto das obras, as menções espaciais destacam atributos naturais e elementos/compartimentos urbanos de Curitiba, todos eles anteriores ao processo implantado pelo seu urbanismo a partir de 1966 e seu corolário iconográfico. Ainda que pareça apressada, a leitura que se pode fazer é a de que a memória e a nostalgia suplantam a crítica. As menções urbanas aí encontradas, mais que isso, retratam uma Curitiba construída em longo processo histórico, pouco resultante de planos ou diretrizes urbanísticas. De um lado, a perenidade do ambiente natural da cidade representada por seus rios; de outro, elementos arquitetônicos e urbanos constituídos não pela intencionalidade dos seus projetos - como veria ser o caso daqueles do modelo Curitiba -, mas sim por coletivos e histórias pessoais.

Outra singularidade dos elementos/compartimentos urbanos encontrados nas obras selecionadas é a sua concentração em um raio aproximado de um quilômetro em área central da cidade, reforçando a resistência a uma Curitiba contemporânea e não necessariamente a uma Curitiba de um modelo urbanístico que se impunha. De fato, nenhuma das referências que estariam mais diretamente relacionadas com intervenções da gestão pública municipal é posterior aos anos 1940. A Praça Tiradentes confunde-se com a própria criação da cidade, em 1693, e passa por diversas reformas, mas é praticamente ignorada pelas discussões do urbanismo municipal, até uma reforma maior que ocorreria apenas em 2008; o Passeio Público, inaugurado em 1886; o Jardim Zoobotânico Municipal, localizado na área central, não é motivo de intervenções remodeladoras no período analisado, ao contrário, é tomado como importante ativo urbano; a Estação Ferroviária de Curitiba, seguindo um processo de falência desse modal nas cidades brasileiras, é fechada e transferida para novo prédio, esse sim um marco da nova estrutura da cidade, em 1972; o Hospital Psiquiátrico Nossa 
Senhora da Luz, inaugurado em 1903, passa desapercebido pela gestão pública municipal; a Praça General Osório, criada em 1874, mantém-se como tal; Largo e Igreja da Ordem, integrantes da história da fundação da cidade, são incorporados ao processo de valorização da área histórica de Curitiba, recebendo equipamentos e serviços urbanos; o Instituto de Educação do Paraná, inaugurado em 1876 é mantido daquele modo (Curitiba, 2017).

Outra maneira de se compreender as referências urbanas encontradas nas obras selecionadas é por meio da sua categorização a partir dos atributos aportados pelo autor em descrições de características socioeconômicas; descrições literais do espaço; e transformações urbanas.

A maior concentração de menções sobre espaços urbanos dá-se, esperadamente, em situações sociais e econômicas dos personagens, sendo complementada pela descrição de tais espaços. Do total de 105 menções encontradas, aproximadamente $80 \%$ estariam classificados nestas categorias. $\mathrm{O}$ restante das menções compreenderia eventuais críticas a uma nova Curitiba, referências de uma Curitiba do passado, e rejeições a uma cidade que, inerentemente, se transforma. Estão praticamente ausentes, na menção explícita do texto, referências à iconografia trazida por um urbanismo tangível, feito por projetos e claramente intencionado a criar referências.

Conforme já visto, as menções a elementos/compartimentos urbanos identificados nas obras selecionadas constroem uma geografia limitada, com pouca distinção para cada uma das décadas analisadas, mesmo frente a uma cidade que enfrenta um processo de metropolitanização e a uma região que conta com taxas de crescimento urbano mais elevadas entre suas similares no cenário nacional (Moura; Firkowski, 2014). O Mapa 1 a seguir revela esse restrito recorte geográfico; se sobreposto a uma mancha urbana formada pelo espraiamento dos 18 municípios que a constituíam no começo dos anos 1990, a limitação é ainda mais evidente. 


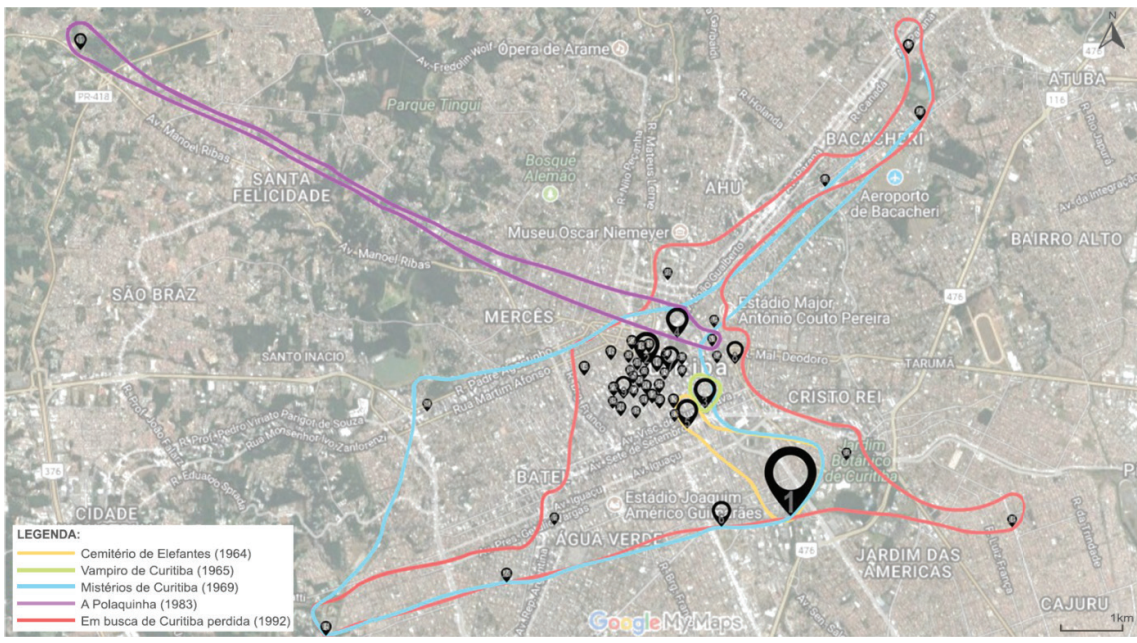

Mapa 1 - Síntese de compartimentos urbanos citados nas obras selecionadas

Nota: Representações gráficas referentes a cada obra analisada foram construídas em plataforma online e estão disponibilizadas nos respectivos links: Cemitério de Elefantes (<https://goo.gl/z1rvLh $>$ ); Vampiro de Curitiba (<https://goo.gl/oCe9p0>) ; Mistérios de Curitiba (<https://goo.gl/DaZq4T>); A Polaquinha (<https://goo.gl/1K7xD3>); Em busca de Curitiba perdida (<https://goo.gl/vpVAS9 >).

Fonte: Elaborado pelos autores, 2017.

Por meio de seus personagens e suas realidades, que em momento algum fazem alusão ao desenvolvimento observado na cidade posteriormente à década de 1960, o autor imprime sua visão daquela cidade que, para ele, seria considerada a "verdadeira Curitiba”. Personagens das obras selecionadas não frequentam os novos marcos locais responsáveis por títulos pretensiosos como a "Capital de Primeiro Mundo"; ao contrário, permanecem em porções centrais, pouco identificados com o novo urbanismo curitibano. Nicolatto (2004, p. 132) ressalta a busca de Trevisan por reinventar acontecimentos da "cidade da memória" reafirmando seu modelo ideal de cidade a partir de um inventário de imagens do passado, consolidando "o poder da memória afetiva e de sensações como um ato de resistência e de denúncia diante do esfacelamento do espaço e das identidades". O mesmo autor reitera o posicionamento distópico de Trevisan quanto às transformações urbanas de Curitiba, situando-se numa capital paranaense dos anos 1940 e 1950, e rejeitando aquela que surge a partir do final da década de 1960. 
Esse posicionamento é também notado quando retomamos a análise do Mapa 1, em que foram condensados os compartimentos urbanos conforme as isolinhas para cada uma das obras. A sobreposição delas para os cinco livros examinados e a representação hierárquica por meio do número de citações relativas ao espaço urbano encontradas (quanto maior o número delas, maior a representação no mapa) confirma uma geografia trevisiana distinta daquela que se tem como a grande Curitiba e aquela que teria sido criada por seu novo urbanismo. A delimitação das "Curitibas" de diferentes décadas, conforme suas experiências urbanísticas, também se mostrou propositada, tácita ou criticamente distinta da Curitiba-personagem.

\section{Considerações finais}

O objetivo principal deste artigo foi o de exercitar os potenciais que se acreditam existir na aproximação interdisciplinar dos campos de estudo do urbanismo e da literatura. Iniciou com o pressuposto de que é possível, de modo complementar, o entendimento da cidade pela narrativa literária. Tem como pressuposto também de que o campo da pesquisa literária busca na cidade seu instrumento metodológico de investigação científica; ou o contrário, em que o urbanismo busca na literatura sua fonte ou estratégia de debate, no entanto, é mais incomum.

É certo que a interpretação do espaço urbano e urbanizado inserido no mundo literário tem suas bases a partir das construções analíticas de quem o escreve e, posteriormente, de quem o lê. Em outras palavras, a experiência e a prática do espaço da cidade pelo autor e pelo leitor são fundamentais para a construção e a transferência da ideia por meio da narrativa. A obra de Dalton Trevisan é correntemente relacionada com a cidade de Curitiba e a narrativa crítica deste autor por mais de uma vez tomada como uma veemente rejeição ao seu modelo de urbanismo. Ao declarar que sua Curitiba não é aquela "para inglês ver”, o autor foi facilmente assimilado pelas vozes contrárias a um determinado grupo político e a um conjunto de intervenções e ideias urbanísticas de forma inconteste. Em Um bom conto é pico certeiro na veia (2002), Trevisan poderia sintetizar sua Curitiba como aquela onde "um Raskolnikov te saúda, a mão na machadinha sob o paletó” (p. 72); reforçando a forte imagem com alma eslava. Em A eterna solidão do Vampiro, o fotógrafo 
Nego Miranda (2010), ao buscar imagens que sintetizariam essa cidade, o faz com luz e sombra, sempre nas esquinas de uma limitada geografia, talvez representativa de um mundo urbano maior, talvez explicitamente restrita a um mundo em desaparecimento meio a uma metrópole que se impôs.

Minha ideia não foi lançar luz sobre a misteriosa literatura de Dalton, mas sim realçar esse ar sombrio. Quis reforçar essa coisa densa. Por isso, fiz algumas fotos às 4 da manhã, por exemplo. Não é aquela Curitiba do Bondinho [um dos ícones do novo urbanismo da cidade, implantado nos anos 1970], é uma Curitiba pesada (Miranda apud Agência de Notícia do Paraná, 2012).

Todavia, uma possível relativização da crítica de Dalton Trevisan ao urbanismo da cidade ou mesmo sua inserção em contextos diversos é pouco exercida. Na força da imagem de um urbanismo de espetacularização e nas referências urbanas feitas por um autor reconhecido como verdadeiramente curitibano, resulta tentador uma imediata relação de júbilo ou rejeição recíproca.

[...] se a classe média exultava de satisfação, vozes dissonantes se faziam ouvir não apenas em oposição ao prefeito [Jaime Lerner], mas também à ideia de que a sociedade se modernizava. Escritores, críticos, poetas e jornalistas, como Wilson Martins diziam ser Curitiba "classe média em tudo", ou ainda Dalton Trevisan que lamentava a nova Curitiba, enfeitada com pontos de ônibus de acrílico e quiosques de flores, populosa, fantasiosa e real (Mancini de Boni, 2010, p. 103).

Outras vezes, o entendimento dado à narrativa se distancia por completo de um desejado posicionamento urbanístico, conforme Da Silva (2006, p. 29), que, entre "simulacros e negatividade", atesta:

Essa cidade que o narrador diz viajar tem, como referente sócio-histórico, uma Curitiba de antanho, uma belle époque tardia da primeira metade do século XX, anterior à reurbanização pós-moderna iniciada nos anos setenta que visava à estruturação de uma metrópole. É uma cidade marginal e provinciana, em franco desaparecimento na segunda metade do século XX; enfim, uma Curitiba perdida.

Em todos os casos, para a perspectiva da literatura como ferramenta ou fonte investigativa do campo urbanístico, vale a suscitação de questões 
provocadoras de um debate necessário. Ainda que seja frágil a identificação de uma forte crítica a um determinado modelo urbanístico nas obras selecionadas de Dalton Trevisan, há certamente alertas relativos para a importância da preservação da memória urbana.

Curitiba é sua matéria. A cidade cresce e se modifica, e sua obra a acompanha cotidianamente, no mesmo processo de destruição e construção típico da cidade moderna. Absorve a diversidade sem abdicar dos fragmentos do passado, se a rua das Flores espetaculariza o contraste e a convivência harmoniosa entre os velhos casarões tombados, os edifícios modernosos das décadas de 40 e 50 e os quiosques e floreiras pós-modernos, no âmbito da linguagem literária o mesmo se dá de maneira mais sutil (Comitti, 1996, p. 86).

Há também alertas para a constituição múltipla de uma cidade, sempre arredia a sínteses universalizantes, com particularidades nem sempre facilmente vistas, nem sempre desejadamente consideradas por oficialidades. Na geografia e na narrativa urbanas identificadas nas obras selecionadas de Dalton Trevisan, sempre buscadas como explicitações de um posicionamento em relação ao urbanismo iconográfico de Curitiba, encontra-se menos coisas. No "enxugamento" de explicitações polarizadas sobre o tema, uma abundância de provocações para se debater a cidade.

1. "A própria narrativa é uma forma de mapear, organizar os dados da vida em padrões reconhecíveis, entendendo que o resultado é uma ficção, uma mera representação do espaço e do lugar, cuja função é ajudar o espectador ou cartógrafo, como leitor ou escritor, a entender o mundo."

2. "Se o escritor é cartógrafo, o crítico é um leitor de mapas, que (como todos os leitores de mapas) também cria novos mapas no processo."

3. "capaz de fornecer uma possibilidade metodológica, mais precisamente: ferramentas para explorar e analisar a geografia particular da literatura”.

4. “O país de um escritor é um território dentro de seu próprio cérebro, e corremos o risco de decepcionarmos se tentarmos transformar essas cidades fantasmas em tijolos e argamassa tangíveis".

5. "A cartografia moderna tem a capacidade de mapear quase todos os fenômenos para os quais as relações espaciais são de 
importância primordial. Enquanto os produtos cartográficos existentes já abrangem uma enorme variedade de tópicos, a visualização de "outras" geografias está ganhando cada vez mais atenção."

\section{Referências}

aGÊNCIA DE NOTÍCIA DO PARANÁ - ANP. Obras de Dalton Trevisan ganham mostras de filmes e fotografias. Cultura. 13 jun. 2012. Disponível em: <http:// www.aen.pr.gov.br/modules/noticias/article.php?storyid=69432\&tit=Obras-deDalton-Trevisan-ganham-mostras-de-filmes-e-fotografias>. Acesso: em 29 out. 2017.

BACHELARD, G. A epistemologia. Lisboa, Portugal: Edições 70, 2006.

BROCA, J. B. Teatro das letras. Campinas, São Paulo: Ed. UNICAMP, 1993.

CARVAlHO, A. S. Curitiba: imagem do planejamento ou planejamento da imagem? 2008. 99 f. Monografia (Graduação em História) - Departamento de História, Universidade Federal do Paraná, Curitiba, 2008.

. O urbanismo e discursos modelares da Curitiba contemporânea. Revista Vernáculo, Curitiba, n. 26, jul./dez. 2010.

. A cidade reinventada: o papel do turismo urbanístico em Curitiba. In: ENCONTRO NACIONAL DA ANPUR, 15., 2013, Recife. Anais... Belo Horizonte: Associação Nacional de Pós-Graduação em Planejamento Urbano, 2013.

COMITTI, L. Anjo mutante: o espaço urbano na obra de Dalton Trevisan. Literatura e Sociedade, Departamento de Teoria Literária e Literatura Comparada da USP, São Paulo, n. 1, 1996.

CRESTANI, A.; ULTRAMARI, C.; OLIVEIRA, J. Diálogo sobre a cidade entre Filosofia, Arquitetura e Urbanismo. Curitiba: Champagnat, 2017.

CURITIBA (Prefeitura Municipal). Informações históricas sobre a cidade. Disponível em: <http://www.curitiba.pr.gov.br/idioma/portugues/pracaosorio>. Acesso em: 25 dez. 2017.

DA SILVA, M. R. P. da S. Simulacro e negatividade: a intertextualidade de Em Busca de Curitiba Perdida, de Dalton Trevisan. Acta Sci. Human Soc. Sci., Maringá, v. 28, n. 1, p. 27-36, 2006. Disponível em: <http://eduem.uem.br/ojs/ index.php/ActaSciHumanSocSci/article/viewFile/179/129>. Acesso em: 17 dez. 2017.

ECO, U. Obra aberta: forma e indeterminação nas poéticas contemporâneas. São Paulo: Perspectiva, 2008.

FELDMAN, S. Avanços e limites na historiografia da legislação urbanística no Brasil. Revista Brasileira de Estudos Urbanos e Regionais (ANPUR), Brasil, v. 4, p. 33-48, 2001. Disponível em: <http://unuhospedagem.com.br/revista/rbeur/ index.php/rbeur/article/view/55/39>. Acesso em: 17 set. 2017. 
. Entre o regional e o metropolitano: pensamento urbanístico e metrópole no Brasil na década de 1950. Revista USP, v. 134, p. 13-22, 2014. Disponível em: $<$ http://www.revistas.usp.br/revusp/article/view/97624>. Acesso em: 17 set. 2017.

GALINDO, C. Invisibilidade: ele mora aqui do lado. Jornal Cândido, Curitiba, Biblioteca Pública do Paraná, n. 11, p. 10-11 2011. Disponível em: <http://www. candido.bpp.pr.gov.br/arquivos/File/candido11.pdf>. Acesso em: 11 jun. 2017

IRAZABAL, C. Desenho urbano, planejamento e políticas de desenvolvimento em Curitiba. Nova Iorque: Columbia University Press, 2013.

JAZAR, M. M. Uni e transtemporalidade na transferência de ideias sobre a cidade: um diálogo sobre a gestão urbana e a obra literária de Graciliano Ramos. 2015. 157 f. Dissertação (Mestrado em Gestão Urbana) - Programa de Pós-Graduação em Gestão Urbana, PUCPR, Curitiba.

KOKULA, R. R. I. Mapping Joaquín: How Literary Cartography Opens New Perspectives on the Western Novel, Papers \& Publications: Interdisciplinary Journal of Undergraduate Research: v. 5, Article 10, 2016. Disponível em: $<$ http://digitalcommons.northgeorgia.edu/papersandpubs/vol5/iss1/10 > . Acesso em: 04 dez. 2017.

LEFEBVRE, H. A revolução Urbana. Belo Horizonte: UFMG, 1999.

. La production de l'espace. Paris: Ed. Anthropos, 1974.

LEME, M. C. da S. A formação do pensamento urbanístico no Brasil: 1895-1965.

In: (Org.). Urbanismo no Brasil 1895-1965. São Paulo: Studio Nobel/FAU USP/FUPAM, p. 20-39, 1999.

MANCINI DE BONI, M. I. Gilda e a arte da existência. In: RAGO, Elizabeth. Foucault e as estéticas da existência. Revista Aulas, Campinas, Editora UNICAMP, n. 7, 2010.

MATIAS, E. S. As representações do contista paranaense Dalton Trevisan da cidade de Curitiba, construída ideologicamente como cidade-modelo, a partir da análise de alguns contos escritos entre 1959 e 2010. 2013. 69 f. Monografia (Especialização em Literatura Brasileira e História Nacional) - Universidade Tecnológica Federal do Paraná, Curitiba, 2013.

MARTINS, I. do M. M. A Geografia da cidade e das transformações urbanas na obra de Fiódor Dostoiévski: o espaço em Os Irmãos Karamázov. Boletim Goiano de Geografia, Goiânia, v. 37, n. 3, p. 509-527, set./dez. 2017.

MIRANDA, N. A eterna solidão do Vampiro. Curitiba: Cultural Office, 2010.

MOURA, R.; FIRKOWSKI, O. (Org.). Curitiba: transformações na ordem urbana. Rio de Janeiro: Letra Capital: Observatório das Metrópoles, 2014.

MUGGIATI, R. Memória: cidade de Dalton. Jornal Cândido, Curitiba, Biblioteca Pública do Paraná, n. 11, p. 16-19, 2011. Disponível em: < http://www.candido. bpp.pr.gov.br/arquivos/File/candido11.pdf>. Acesso em: 11 jun. 2017. 
NASCIMENTO, L. Cartografias Literárias Urbanas em Eça de Queiroz. Revista Ininga, Teresina, v. 1, n. 1, 2014. Disponível em: <http://www.ojs.ufpi.br/index. php/ininga/article/view/3187/1807>. Acesso em: 27 nov. 2017.

NICOLATO, R. Em busca de Curitiba perdida: resistência e memória no inventário de Dalton Trevisan. Revista Letras, Curitiba, v. 21, n. 64, p. 125141, set./dez. 2004. Disponível em: <http://revistas.ufpr.br/letras/article/ viewFile/2973/2401>. Acesso em: 17 dez. 2017.

PIATTI, B.; REUSCHEL, A-K.; HURNI, L. Literary Geography, or How Cartographers Open up a New Dimension for Literary Studies. In: INTERNATIONAL CARTOGRAPHIC CONFERENCE, 24${ }^{\text {th }}$ 2009, Santiago do Chile. Anais... Budapest, Hungary: International Cartographic Association, 2009. Disponível em: <http://icaci.org/files/documents/ICC_proceedings/ ICC2009/html/nonref/24_1.pdf>. Acesso em: 04 dez. 2017.

PIATTI, B. et al. Mapping Literature: Towards a Geography of Fiction. Relatórios do Projeto A Literary Atlas of Europe. Institute of Cartography and Geoinformation, ETH Zurich. 2012. Disponível em: < http://www.literaturatlas. eu/files/2012/01/Piatti2008_ArtAndCartography_Springer.pdf $>$. Acesso: 05 dez. 2017.

PONTES, M. de M. e. Jorge Amado e a Literatura de Combate: da Literatura de engajada à Literatura Militante de Partido. Revista de Educação, Linguagem e Literatura, Inhumas, Goiás, v. 1, n. 2, out. 2009.

PRESTES. O. A transparência das ideias em estudos e gestão da cidade contemporânea pela perspectiva do transporte coletivo: um estudo de caso na cidade de Curitiba/PR. 2018. 256f. Tese (Doutorado em Gestão Urbana) Programa de Pós-Graduação em Gestão Urbana, PUCPR, Curitiba, 2018.

RABENHORST, E. R. Sobre os limites da interpretação. O debate entre Umberto Eco e Jacques Derrida.Prim@Facie, João Pessoa, Paraíba, ano 1, n. 1, jul./dez. 2002.

REBINSKI, R. Especial: Dalton Trevisan e Rubem Fonseca. Revista Cândido, Curitiba, Biblioteca Pública do Paraná, v. 72, 2009.

ROSAlinO, R. B. Dalton Trevisan e o projeto estético minimalista. 2002. 128 f. Dissertação (Mestrado em Literatura) - Universidade Federal de Santa Catarina, Florianópolis, 2002.

SANCHES NETO, M. A reinvenção da provincia: a revista Joaquim e o espaço de estreia de Dalton Trevisan. 1998. 448 f. Tese (Doutorado em Teoria Literária) - Instituto de Estudos da Linguagem, Universidade Estadual de Campinas, Campinas, São Paulo. Disponível em: <http://libdigi.unicamp.br/ document/?code=000130045>. Acesso em: 17 dez. 2017.

SANCHEZ, F. A cidade espetáculo: política, planejamento e city marketing. Curitiba: Editora Palavra, 1997.

SANTOS, M. Tendências da urbanização brasileira no fim de século XX. In: CARLOS, A. F. A. (org). Os caminhos da reflexão sobre a cidade e o urbano. São Paulo: Edusp, 1994. 
SIMMEL, G. The metropolis and mental life. In: SENNETT, Richard (Ed.). Classic essays on the culture of cities. New York: Appleton-Century-Crofts, 1969.

SOUZA, R. et al. Literatura e Cinema: Encontros Contemporâneos. Porto Alegre: Editora Dublinense, 2013.

STROHER, L. E. M. Trajetória do planejamento urbano na Curitiba-metrópole: o Impasse da reforma urbana na "cidade-modelo". In: SEMINÁRIO INTERNACIONAL RII, 8., 2014, Salvador. Anais... Cidade do México: Red Iberoamericana de Investigadores sobre Globalización y Territorio, 2014.

SZUCHMAN, T. Fragmentação e (re)composição na migração de ideias sobre cidades: as trajetórias do Modelo Curitiba. 2017. 218 f. Tese (Doutorado em Gestão Urbana) - Programa de Pós-Graduação em Gestão Urbana, PUCPR, Curitiba, 2017.

TALLY JR, R. T. On Literary Cartography: Narrative as a Spatially Symbolic Act. New American Notes Online. 2011. Disponível em: < https://nanocrit.com/ issues/issue1/literary-cartography-narrative-spatially-symbolic-act>. Acesso em: 28 nov. 2017.

TREVISAN, D. [1959] Novelas nada exemplares. Rio de Janeiro: Record, 1979. . [1964] Cemitério de Elefantes. Rio de Janeiro: Record, 2009. .[1965] O Vampiro de Curitiba. Rio de Janeiro: Record, 2004. . [1968] Mistérios de Curitiba. Rio de Janeiro: Record, 2004. . [1983] A polaquinha. Rio de Janeiro: Record, 1985. . Em Busca de Curitiba Perdida. Rio de Janeiro: Record, 1992. . Um bom conto é pico certeiro na veia. Rio de Janeiro: Record, 2002.

TURCHI, P. Maps of the Imagination: The Writer as Cartographer. San Antonio, TX: Trinity UP, 2004. 7. print.

ULTRAMARI, C.; CIFFONI, A. L. The far distant city of Paris and someone called Haussmann. Diálogos, Maringá, v. 19, n. 3, p. 1371-1388, set./dez. 2015. Disponível em: <http://www.uem.br/dialogos/index.php?journal=ojs\&page=ar ticle\&op=view\&path\%5B\%5D=1097\&path\%5B\%5D=pdf_791>. Acesso em: 28 nov. 2017.

ULTRAMARI, C.; FIRKOWSKI, O. L. Sobre mudanças e continuidades na gestão urbana brasileira. Revista Mercator, Fortaleza, v. 11, n. 24, 2012.

ULTRAMARI, C.; JAZAR, M. Literatura e Cidade: campo interdisciplinar e vazios investigativos. Cadernos de Pesquisa, São Luís, v. 23, n. 2, mai./ago. 2016. Disponível em: <http://www.periodicoseletronicos.ufma.br/index.php/ cadernosdepesquisa/article/view/5348/3271>. Acesso: 06 dez. 2017.

VIEIRA, N. H. Espaço vivido e espaço mental: Dalton Trevisan e a dicotomia social do urbanismo curitibano. Estudos de literatura Brasileira Contemporânea, Brasília, n. 42, p. 151-167, jul./dez. 2013. 
WALDMAN, B. Do vampiro ao cafajeste: uma leitura da obra de Dalton Trevisan. São Paulo: Hucitec; Curitiba: Secretaria da Cultura e do Esporte do Governo do Estado do Paraná, 1982.

. Tiro à queima-roupa. Novos Estudos, São Paulo, CEBRAP, n. 77, p. 255259, mar, 2007. Disponível em: <http://www.scielo.br/scielo.php?script=sci arttext\&pid $=$ S0101-33002007000100014\&lng $=$ en\&nrm=iso $>$. Acesso em: 3 ago. 2017

WOOLF, V. Literary geography. In: MCNEILLIE, A (Ed.). The essays of Virginia Woolf, 1986. p. 28-42.

Clovis Ultramari - É arquiteto, doutor em Meio Ambiente e Desenvolvimento Urbano pela Universidade Federal do Paraná. Pesquisador do PPGTU/Pontifícia Universidade Católica do Paraná, atualmente com projetos, publicação e orientação nas áreas relativas a questões conceituais e epistemológicas da cidade. ORCID: https://orcid.org/0000-0002-6441-3547.

Manoela Massuchetto Jazar - É arquiteta, mestra em Gestão Urbana. Doutoranda no PPGTU/Pontifícia Universidade Católica do Paraná, desenvolve pesquisas sobre circulações de ideias no espaço urbano e relações entre cidades e literatura. ORCID: https://orcid.org/0000-0002-7627-8346.

Diego Luís Fock Pereira - É arquiteto. Mestrando no PPGTU/ Pontifícia Universidade Católica do Paraná, dedica-se a pesquisas sobre metodologias urbanas. ORCID: https://orcid.org/0000-0001-5478-6318.

\section{Contribuições dos autores}

Clovis Ultramari e Manoela Massuchetto Jazar ficaram especialmente responsáveis pelo desenvolvimento teórico-conceitual; Diego Luís Fock Pereira, pela aquisição de dados e suas interpretações e análises. Aos três autores são atribuídas as delimitações dos procedimentos técnicos da pesquisa. 